\title{
DOS DIBUJOS DE DOMENICHINO PARA LA IGLESIA ROMANA DE SAN CARLO AI CATINARI
}

Recientemente salieron a la venta en el comercio ${ }^{1}$ sevillano dos bellísimos dibujos (Figs. 1 y 2) atribuidos al pintor Domenico Zampieri, más conocido como Domenichino ${ }^{2}$ (15811641). Se trata de sendos dibujos preparatorios para unas pechinas cuyo asunto se ha querido identificar con la representación de Palas Atenea (sanguina, $440 \times 460 \mathrm{~mm}$ ) y una Diosa (sanguina, $460 \times 440 \mathrm{~mm}$ ).

Aunque la atribución al pintor boloñés es indudable, no parece correcta la identificación iconográfica de los dibujos. En realidad, representan sendas alegorías de la Justicia y la Prudencia respectivamente, dibujos preparatorios para dos de las pechinas de la iglesia romana de San Carlo ai Catinari.

La iglesia de San Carlo ai Catinari ${ }^{3}$, así llamada por los fabricantes de cántaros que ocuparon la zona durante largo tiempo, tiene su origen en una antigua iglesia dedicada a San Biaggio de Oliva. Sobre el solar del templo se edificó a partir de 1612 una monumental iglesia dedicada a San Carlos Borromeo según trazas de Rosario Rosati, cerrándose la cúpula en 1620. La fachada se completó entre 1636-1638 según planos de Giovanni Battista Soria, y el ábside se cerró entre 1638-1646. La iglesia sería finalmente consagrada en 1722.

La decoración interior se prolongaría hasta fines del siglo XVII. Además de la decoración de las pechinas, ejecutadas por Domenichino entre 1627-1630, Mattia y Gegorio Pretti decoraron al fresco entre 1641-1642 la contrafachada con episodios de la vida de San Carlos Borromeo. El ábside fue decorado por Lanfranco en 1646 con el tema de la Gloria de San Carlos Borromeo, y para el altar mayor se encargó a Pietro da Cortona el gran cuadro de San Carlo che porta in processione il Sacro Chiodo. No puede olvidarse la Capilla de Santa Cecilia, obra del artista reatino Antonio Gherardi ${ }^{4}$, realizada entre 1692-1700.

Existe un bellísimo aguafuerte fechado en 1756 de mano de Giuseppe Vasi que permite contemplar la apariencia de la iglesia y su entorno tres décadas después de su consagración. La estampa se incluye dentro de su obra Sulle magnificenze di Roma Antica e Moderna ${ }^{5}$ (17471761), dedicada al monarca español Carlos III.

La decoración de las pechinas de San Carlo ai Catinari se realizó como ya se ha dicho entre 1627-1630. En ellas se representaron las Cuatro Virtudes Cardinales —Justicia, Templanza, Fortaleza y Prudencia -, si bien la alegoría de la Templanza fue completada en 1630 por Francesco Cozza.

No hay duda alguna respecto a la filiación de los dibujos con la decoración de San Carlo. A parte de los propios frescos, contamos con un documento excepcional que así lo corrobora. Se trata de cuatro aguafuertes (Figs. 3 y 4) de Pietro del Pó (1610-1692) conservados en el Istituto Nazionale per la Grafica de Roma ${ }^{6}$ (668 x $518 \mathrm{~mm}$ cada uno) que reproducen fidedignamente los dibujos de Domenichino aparecidos en el comercio sevillano.

No son los únicos diseños conocidos del pintor boloñés en España. En la Real Academia

\footnotetext{
${ }^{1}$ Arte Información y Gestión, Subasta de Arte y Joyas, 20 de noviembre de 2003, p. 89, lote 268.

${ }^{2}$ Sobre Domenichino ver: Spear, Richard E.: Domenichino, London, New Haven, 1982; Borea, Evelina: Domenichino, Edizioni per il Club del Libro, Milano, 1965. Sobre las obras del artista en España ver: Pérez Sánchez, Alfonso E.: Pintura Italiana del siglo XVII en España, Madrid, 1965, pp. 123-135.

${ }^{3}$ Ver: Lunghi, Martino: Architettura Barocca a Roma, Roma, ed. Bulzoni, 1972.

${ }^{4}$ Recientemente se ha dedicado una bellísima exposición al artista en su ciudad natal, Rieti: Antonio Gherardi, artista reatino (1638-1702). Un Genio bizzarro nella Roma del Seicento. Rieti, Palazzo Papale, 27 giugno-28 settembre 2003.

${ }^{5}$ Libro VII. I Conventi e case dei chierici regionale (1756), mapa 3C, giorno 7, vedutta C8.

${ }^{6}$ Exposición: Incisori napoletani del'600. Istituto Nazionale per la Grafica, Roma, Villa Farnesina, 19 marzo-24 maggio 1981, pp. 180-181, $\mathrm{n}^{\circ}$ cat. 172.
} 

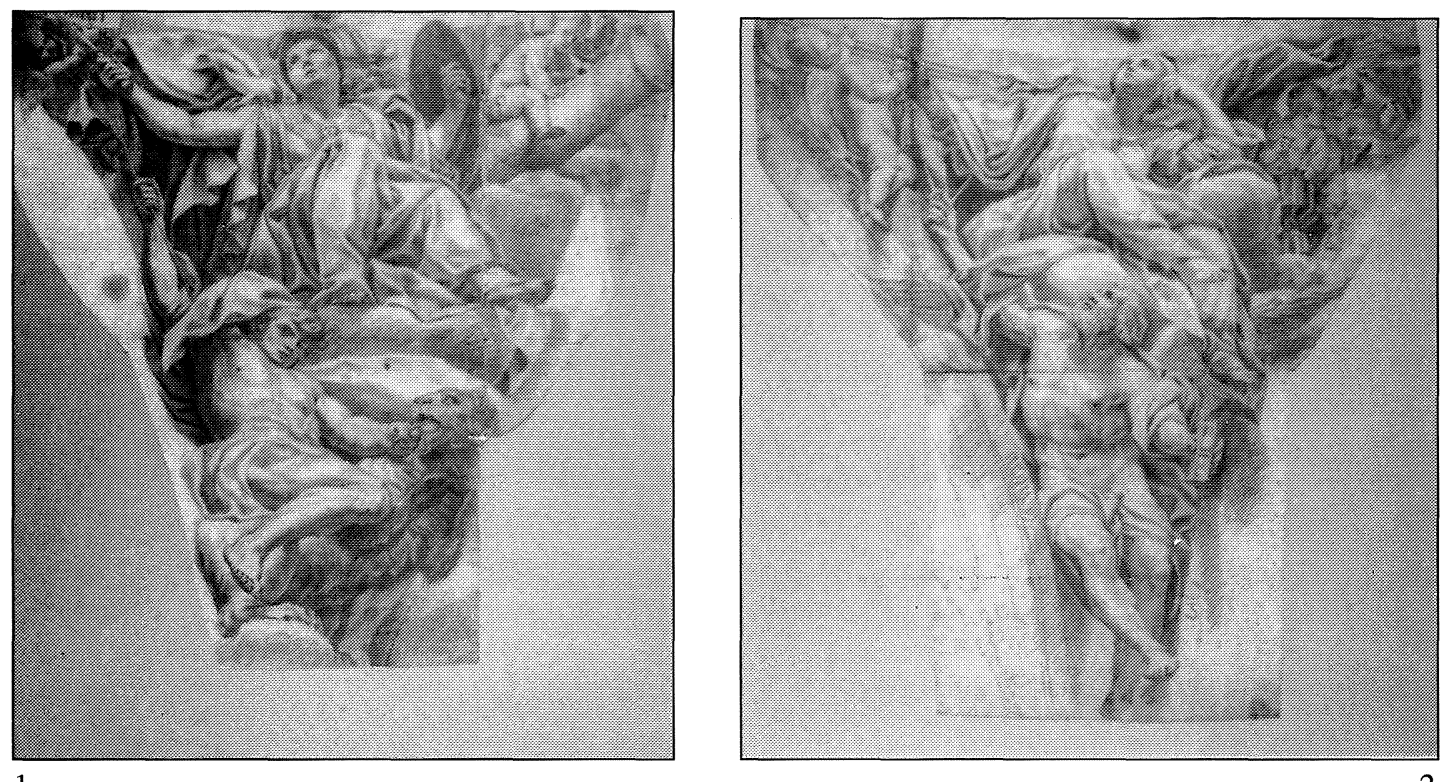

1 2

3

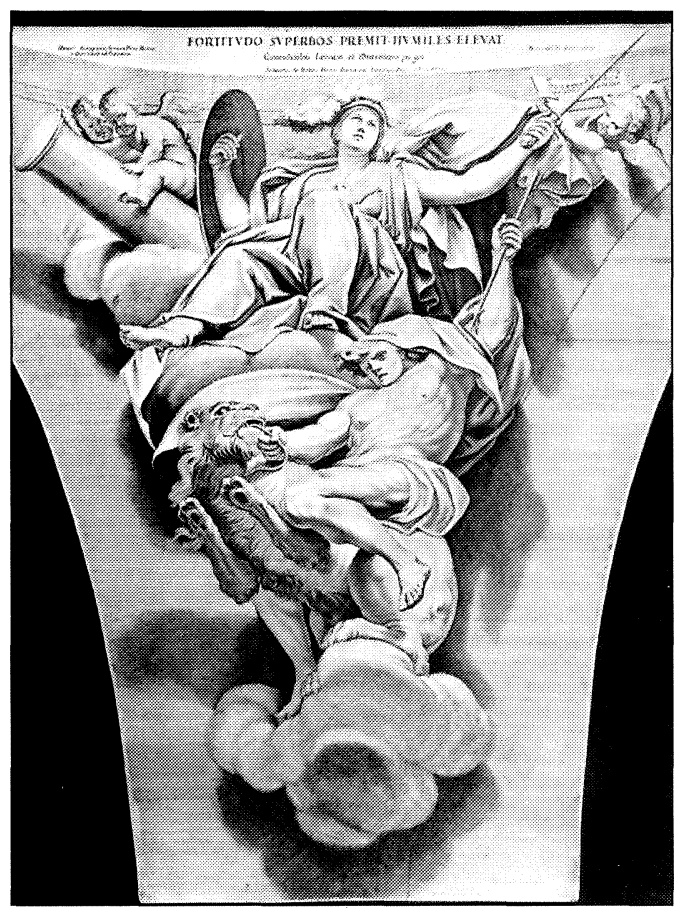

4

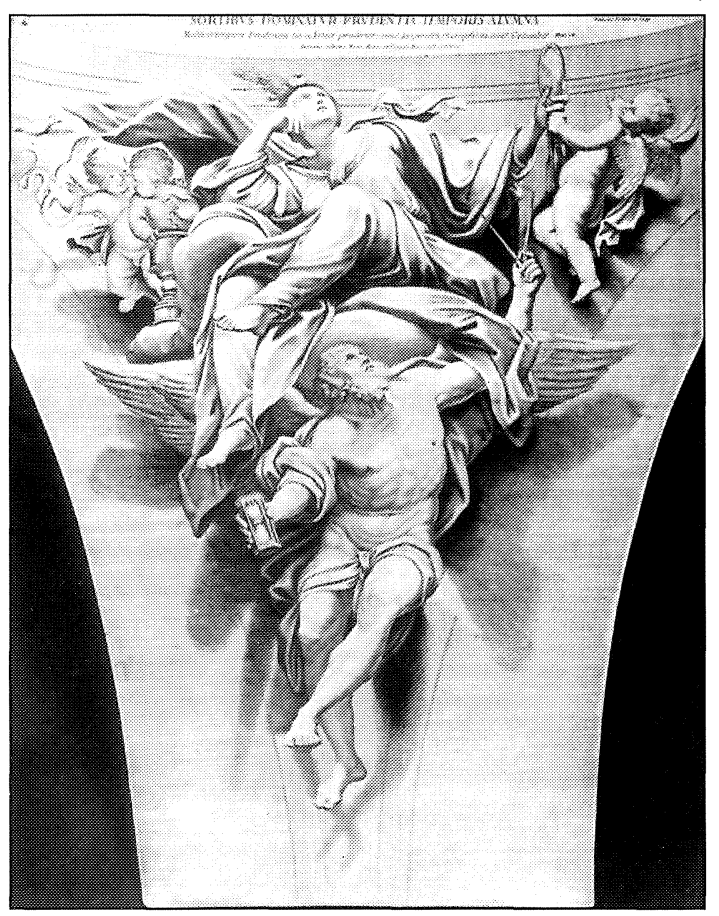

Fig. 1. Domenichino: Alegoría de la Justicia $(440 \times 460 \mathrm{~mm}$.). Madrid, Comercio.

Fig. 2. Domenichino: Alegoría de la Prudencia $(460 \times 440 \mathrm{~mm}$.). Madrid, Comercio.

Fig. 3. Pietro del Pó: Alegoría de la Justicia $(668 \times 518 \mathrm{~mm}$.). Roma, Istituto Nazionale per la Grafica.

Fig. 4. Pietro del Pó: Alegoría de la Prudencia $(668 \times 518 \mathrm{~mm}$.). Roma, Istituto Nazionale per la Grafica.

$A E A$, LXXVIII, 2005, 309, pp. 83 a 105 
de Bellas Artes de San Fernando se conservan sendas sanguinas ${ }^{7}$ que representan respectivamente a San Mateo $(427$ x $510 \mathrm{~mm})$ y San Marcos $(475 \times 533 \mathrm{~mm})$. Como en el caso que nos ocupa, se trata de dos dibujos preparatorios para las pechinas de la también iglesia romana de Sant'Andrea della Valle, pintadas al fresco entre 1624-1628 en el punto álgido de su carrera.

Quizás habría que relacionar estos dibujos con las pechinas —en lienzo- del Convento de Carmelitas de Toledo, copia de los frescos de Sant'Andrea. Pérez Sánchez ${ }^{8}$ piensa que los lienzos pudieron ser realizados en la propia Roma a tenor de la calidad de la copia y al hecho de que el copista fue fiel a la hora de interpretar los colores, hecho que descarta, como se señala, el empleo de estampas.

ÁNGel RodRíGuez ReBollo

Fundación Universitaria Española

\footnotetext{
${ }^{7}$ Ambos dibujos fueron presentados en la Exposición: El dibujo europeo en tiempos de Velázquez. A propósito del retrato del Cardenal Borja de Velázquez de la Real Academia de Bellas Artes de San Fernando, Madrid, diciembre de 1999enero de 2000, p. $77, n^{\circ}$ cat. 25 y p. $78, n^{\circ}$ cat. 26.

${ }^{8}$ Pérez Sánchez (1965), p. 130.
} 